true vocation in doing them. But the chance of promotion for the industrial nurse was never greater than it is now. The facilities for education and training are becoming better known and more widely available, and in time the highest posts will be open to all who are fitted to fill them.

\section{WOUND INFECTION IN INDUSTRY}

The treatment of minor injuries occurring at the place of work is an important part of the work of the industrial medical officer and his nurses. The higher the standard of treatment in the factory the less is the risk of sepsis, with its consequent absence from work and increase in permanent disablement. The treatment of major wounds is largely the responsibility of the hospitals, and with that side of the problem we are not concerned here. But the millions of minor injuries that occur annually are injuries that cause no loss of time-and within industry itself present a challenge to the medical officer. For many years he has worked alone in this field. He has frequently improved conditions because his standards are obviously far beyond those of the first-aid worker who dabbles in the subject-often as a hobby but so often to the detriment of the injured man. But in this matter of wound treatment he needs help, particularly from the bacteriologist; and he needs advice from his surgical colleagues, if only from one point of view - what to leave alone.

When we consider that even to-day most workpeople have no nurses and doctors to superintend the treatment of accidents at work the problem becomes serious in terms of manpower and production. S. A. Henry, in his recent Milroy Lectures, ${ }^{1}$ tells us that the actual number of reportable factory accidents in which sepsis supervened increased from approximately $21 \frac{1}{2}$ thousand in 1939 to $22 \frac{1}{2}$ thousand in 1942; the large increase in the numbers employed reduced the percentage figure from 11 to $10 \cdot 3$. It would be interesting to know the criteria upon which the diagnosis of 'sepsis' is made. Because of the apparent absence of definition this figure is unlikely to represent the true state of affairs, and it is an interesting fact that there is no obligation uron the employer specifically to report such cases. In many instances the diagnosis of ' sepsis' is left to the firstaid worker and the untrained nurse-and often to a welfare supervisor or an office clerk-who may be the main contact on such matters with the firm's insurance company or the Factory Department of the Ministry of Labour. But even so, it is one index of the incidence of wound infection in industry, an incidence which is probably higher than published figures suggest. It is to be hoped that more accurate figures will one day be available, not only from factories but from other industries such as mining, docks, construction, ship-yards, and the various transport services. But until we can get the facts we can do little more than guess at a figure.
Those who are engaged in industrial medicine therefore welcome the decision of the Medical Research Council to set up a bacteriological unit at the Birmingham Accident Hospital. Here the whole question of wound infection as it affects industry will be closely studied in conjunction with clinicians skilled in accident treatment, with industrial doctors and with nurses. In this issue we publish from the unit one of a series of studies on the problem by Gissane, Miles and Williams. It refers specially to the design of dressing stations. They tell us that many wounds are already septic when first seen in the factory surgery, and that a proportion of open wounds become septic during treatment. We would observe that, just because so many wounds are not seen by the nurses or the doctor in industry until they are in fact septic, health education and propaganda on the prevention of wound infection become a matter of the first importance. The difficulties of educating the great masses of workers are not always appreciated, nor, indeed, is it the responsibility of laboratory workers or hospitals. But its significance in this particular problem is clear, and the results of a long-term research such as the Medical Research Council has inaugurated, affecting in one way or another the majority of our working population, must eventually be expressed in plain language. The help of such a body as the Central Council for Health Education might be enlisted for this. Simple rules must be laid down for first treatment, not only that to be carried out by ' the responsible person trained in first-aid treatment '-to quote section 45 of the Factories Act-but that which becomes the responsibility of the nurse and of the industrial doctor himself.

It is interesting to note that 'silent infection,' which may be present in up to 40 per cent. of the wounds treated at the factory, not only delays healing but also forms a reservoir of organisms capable of infecting clean wounds treated in the same surgery. The important point is made that an aseptic technique must therefore be designed to prevent cross-infection from these wounds already septic or 'silently' infected. The authors have wisely attempted to set their own house in order at the hospital and by doing this have anticipated criticism. Indeed the hospital problem, as the Medical Research Council has pointed out in a recent memorandum, ${ }^{2}$ is in itself one which needs looking into. This report showed that, while pyogenic organisms are found in only a small proportion of open wounds examined on admission to hospital (the figures have been 5-6 per cent. in the present war compared with 15-20 per cent. in the last war), the proportion of infected wounds may exceed 50 per cent. after a week's stay in hospital and increases with further residence. These findings have been confirmed in industry.

The difficulty of altering present conditions and of instituting aseptic technique is recognized. But 
the first stage in this direction is the proper planning and lay-out of the industrial dressing station. Without this a suitable technique cannot be established nor infection controlled. The dressing station staff in industry will not at first be prepared to spend time in improvements the value of which only a long-term application will reveal, and Gissane and his colleagues recognize the fact that the works ambulance room is also used for other purposes than wound dressings. The main recommendations, however, must be carefully considered by all those who have the personal responsibility for large numbers of daily dressings.

Another contribution of much interest to industrial medical officers is that of Colebrook, Gibson and Todd on the first-aid treatment of burns. In certain of our industries-for example, the casting of metal-burns are only too common, and the wastage of man-hours from this cause is well recognized. But most burns in industry are not serious enough to need hospital treatment; yet no matter how trivial, every burn is a source of infection. The authors maintain that it is important to distinguish clearly between temporary treatment at the scene of the accident, or first aid, and the further treatment carried out by a doctor or nurse, which they term 'plenary' treatment to convey the idea of completeness. The treatment of burns is intimately bound up with the problems of wound infection, and the main conclusion which Colebrook comes to is that avoidance of infection by the haemolytic streptococcus should dominate first-aid policy for all but very severe burns, where general measures often have to take precedence over local treatment. A simple first-aid measure is recommended-namely, the local use of a water-soluble cream containing 1 per cent. of cetyl trimethyl ammonium bromide and 3 per cent. sulphanilamide. Part of the experimental work has been done within the factory dressing station as well as the hospital, and the arguments in favour of giving an extended clinical trial to this new method are convincing.

The war has underlined the great need for collaboration between the clinician and the bacteriologist in tackling the ever-present problem of wound infection. The two must study the industrial problem at the place where it arises-in the factory, in the mill, in the coalmine, in the workshop. The challenge from industry to medicine must be met, and in industry, at least, the doctor should find a full appreciation of his difficulties as a technician; he may even learn from the industrial technician how best to solve problems which at a superficial glance may seem to be medical only. 